\title{
Seat Belt Compliance and University Students
}

\author{
Wan Noor Haida Wan Ahmad Kamal'1 , Mohamad Ghazali Masuria, \\ Akehsan Dahlan¹, Khairil Anuar Md Isa² \\ ${ }^{1}$ Occupational Therapy Department, Faculty of Health Sciences, \\ 2Basic Sciences Department, Faculty of Health Sciences, \\ Universiti Teknologi MARA, Malaysia.
}

zalie222@gmail.com

\begin{abstract}
Driving, as an instrumental activity of daily living has a positive influence on individual health-related quality of life. A success driving performance will depends on credible drivers, optimum vehicles condition and smart road design. The successful collaboration in between human, machine and environment should encompass two ways 'communication'. However, $95 \%$ of road traffic accident was due to human errors. The purpose of this study is to investigate the seat belt compliance and quality of life among educated young adults in an urban university. Perhaps, this findings could be used to educate young drivers in the future.
\end{abstract}

Keywords:4 seat belt compliance; young adult; quality of life keywords

eISSN: 2398-4279 @ 2017. The Authors. Published for AMER ABRA by e-International Publishing House, Ltd., UK. This is an open access article under the CC BY-NC-ND license (http://creativecommons.org/licenses/by-ncnd/4.0/). Peer-review under responsibility of AMER (Association of Malaysian Environment-Behaviour Researchers), ABRA (Association of Behavioural Researchers on Asians) and cE-Bs (Centre for EnvironmentBehaviour Studies), Faculty of Architecture, Planning \& Surveying, UniversitiTeknologi MARA, Malaysia.

https://doi.org/10.21834/ajqol.v2i7.62 


\subsection{Introduction}

The main function of road transport system is to help and improve people mobility from one place to another. However, this system comes with a significant risk. The most common risks that related with this system is for definite; road traffic accident.. Injury and death resulting from road traffic collisions is a great health problem worldwide. According to Royal Malaysia Police annual report, there were more than 6,000 killed and over 25,000 recorded injuries yearly for the past 7 years. These road injuries and fatalities have become a great concern for Malaysian government. This scenario may due to rapid development in Malaysia (Mohamad Ghazali Masuri, Akehsan Dahlan, Ajau Danis, \& Khairil Anuar Md Isa, 2015). Increasing the number of cars also could increased the number of traffic accidents in directly (Bendak, 2005). There were many causes of accident either it is due to primary or secondary factors. Factors such as speeding, using a mobile phone and not wearing seat belt are considered as a contributing factors for injury and fatality (Mohamad Ghazali Masuri, Akehsan Dahlan, Ajau Danis, \& Khairil Anuar Md Isa, 2015).

RTA may happen due to secondary factor. In a simple meaning, this factor can be translated as 'due to others' or 'somebody mistake'. This factor usually happen unexpectedly. For example, children crossing the road without any notice, other drivers/road users running on red light, turning without giving any signal and etc. This usually contribute to fatal accident. To avoid this potential accident, drivers must be alert at all time. The factor of alertness usually is a combination of few other mental components such as: cognitive, time respond, stress and mental status.

With regards to drivers' safety, seat belt is considered as an effective safety measure to a decrease severity of injuries and reduce the death rates (Lapparent, 2008). Other study has shown that, drivers who violate the seat belt laws are likely to violate other traffic rules and regulation and thus have a higher likelihood for accident involvement (Mohammadi, 2011). Therefore, this paper aims to understand the human factors in the seat belt utilization pattern amongeducated young adult. This study is beneficial to help to overcome this global issue early. Thus, it is significant to strategically plan and develop interventions such as the education or enforcement programs to address the best solutions on how to reduce the issue.

\subsection{Literature Review}

Recent news highlighted in a new report that the rate of car crash fatalities varies across nations. Surprisingly, Malaysia was ranked in a list of the 25 countries with the highest carcrash fatality rate which also accompanied by the number of road accident deaths per 100,000 people. The seat belt utilization among educated young adults has been studied in some parts of the globe. The results revealed that this group of drivers are engaging in unsafe driving behaviours that put their safety and health at risk of injury and fatality. Another example of the unsafe driving behaviour is using mobile phone while driving as this 
study was conducted by Isa et al. (2012) among educated young adults in urban university in Klang Valley, Malaysia. In the early seventies, the enforcement of the mandatory seatbelt law for front occupants was being implemented in Malaysia as cited by Mohamed, Yusoff, Batcha, Othman, \& Abdullah (2010) from (RT0 1958). After the enforcement, the rate of the safety seat belt wearing has increased (Mohamed, et al., 2010). A few studies have been conducted to determine the seatbelt wearing rate in Malaysia. For example, the earliest study on measuring the seat belt wearing in Malaysia was conducted among taxi drivers in 1993 in the city of Kuala Lumpur and found $40 \%$ of seatbelt compliance rate (Hauswald, 1997). While in 2003, a study to determine the status of seatbelt wearing among the car occupants in the state of Selangor and it is shows compliance rate which is $76.6 \%$ for car drivers. Beside, the study on observing wearing rate among rear passenger has been conducted in 2004 and they found that none of the rear passengers wore seatbelts (Kulanthayan, Raha, Law, \& Umar, 2004). Recently, a study conducted by Ng, Law, Wong, \& Kulanthayan (2013) on factors related to seatbelt-wearing among rear-seat passengers in Malaysia. They found that rear seatbelt-wearing was low with about $46 \%$ of rear-seat passengers never wearing a rear seatbelt. Another recent study which conducted by Kulkarni et al. (2013) observed that knowledge regarding seat belt was low among undergraduate medical students in South Indian state. Similarly in Malaysia, Redhwan \& Karim (2010) found that the university students had moderate knowledge about the road traffic regulations which is including the knowledge regarding the seat belt usage.

Driving is a part of instrumental of activity of daily living which is very important for working, educational and leisure. It is a complex and challenging activity which involved eye-hand-foot coordination (Masuri, Md Isa, \& Mohd Tahir, 2012). Being a driver may have a positive influence on health-related quality of life (DeCarlo, Scilley, Wells, \& Owsley, 2003). However, failure to organize and interact with the machine and environment may cause to road traffic injury (RTI) (Masuri, et al., 2012). Human errors are including the unbelted while driving, alcohol consumptions, violations, and others. This is supported by Rakauskas, Ward, \& Gerberich (2009) that one of the factors that associated with the higher fatality crash rate is the attitude and psychological differences between rural and urban drivers in the perception of risk factors. Unbelted is one type of the risk-taking behaviour which may increase the fatality crash rate especially among young adult.

\subsection{Methodology}

This research was embarked with a cross sectional self rated questionnaire survey among educated young adults in urban universities in Selangor. Two pages of self rated driving questionnaire was distributed to a potential respondents. Convenience sampling method was used in the participation selection process. This study was approved by the Faculty of Health Sciences ethical committee. Two urban universities were chosen to participate in this study. Sampling population for this study was carried out on young educated adults, 
male and female with age limit (18-39 years old) and fulfilled the inclusion and exclusion criteria. 408 educated young adults $(n=408)$. The permission and informed consent had been obtained from the office of universities. The samples were voluntary to take part into this study. Data entry and statistical analysis was carried out by using Statistic Program for Social Science (SPSS) Version 18.0.

\subsection{Results and Discussions}

Table 1 shows the basic demographic of the 408 respondents studied. Majority of the respondent were female drivers. Forty-six percent of the respondent can be consider as a new drivers which obtained their driving licence for the past 24 months.

Table 1: Demographic data.

\begin{tabular}{llll}
\hline Variable & Variable & Frequency $(\mathbf{n}=\mathbf{4 0 8})$ & Percentage $(\%)$ \\
\hline Gender & Male & 184 & 45.1 \\
Marital status & Female & 224 & 54.9 \\
& Single & 372 & 91.2 \\
& Married & 32 & 7.8 \\
Education status & Divorced/ Widowed & 4 & 1.0 \\
& Diploma & 36 & 8.8 \\
& Degree & 354 & 86.8 \\
Scholarship & Master & 18 & 4.4 \\
& PTPTN & 180 & 44.1 \\
Licence obtained & JPA & 64 & 15.7 \\
& Others & 164 & 40.2 \\
& $1-2$ & 188 & 46.1 \\
Driving experience & $3-5$ & 178 & 43.6 \\
& $6-8$ & 42 & 10.3 \\
& $<1$ & 62 & 15.2 \\
& $2-5$ & 254 & 62.3 \\
& $6-9$ & 86 & 21.1 \\
& $>10$ & 6 & 1.5 \\
\hline
\end{tabular}

This survey found that only $45.1 \%$ who are always use the seat belt. This rate is significantly lower which not more than half of the total respondents were comply with seat belt regulations. This indicates that educated young adults are exposed to a great risk in traffic crash injuries or event fatality if involves with road traffic accidents. Meanwhile, there are only 114 of the respondents $(27.9 \%)$ who use the seat belt most of the time and 84 out of $408(20.6 \%)$ of total respondents who sometimes use the seat belt while on the road. However, there are only $5.9 \%$ of them who were rarely use the seat belt and $0.5 \%$ who were never belted. Even though there were only small portions $(0.5 \%)$ of the total respondent who never wear seat belt at all, this could be an indicator to further investigate the fundamental reasons of their driving behaviour. 
Table 2: Seat belt utilization and demographic data

\begin{tabular}{|c|c|c|c|c|c|c|c|}
\hline Vanaole & Never (h) & $\begin{array}{l}\text { Rarely } \\
(\%)\end{array}$ & $\begin{array}{l}\text { Sometimes } \\
\text { (\%) }\end{array}$ & $\begin{array}{l}\text { Mroat of the } \\
\text { ime } \\
\text { (\%) }\end{array}$ & $\begin{array}{l}\text { Always } \\
\text { (\%) }\end{array}$ & $\begin{array}{l}\text { Chr } \\
\text { square }\end{array}$ & praloe \\
\hline $\begin{array}{l}\text { Genot } \\
\text { Male }\end{array}$ & $2(1.1)$ & $8(4,3)$ & $48(26.1)$ & $52(28.3)$ & $\begin{array}{l}74 \\
(40.2)\end{array}$ & 10.481 & 0.033 \\
\hline Femse & $0(0)$ & $16(7.1)$ & $36(16.1)$ & $62(27.7)$ & $\begin{array}{l}110 \\
(49.1)\end{array}$ & & \\
\hline $\begin{array}{l}\text { Marital Statua } \\
\text { Single }\end{array}$ & $O(0)$ & $18(48)$ & $74(19.9)$ & $106(26.5)$ & $\begin{array}{l}174 \\
(48.8)\end{array}$ & 218966 & 0.000 \\
\hline $\begin{array}{l}\text { Marred } \\
\text { Oivoroed } \\
\text { Widowed } \\
\text { Edveation Statua }\end{array}$ & $\frac{0(0)}{2(50.0)}$ & $\begin{array}{l}6(18.8) \\
0(0)\end{array}$ & $\begin{array}{l}10(313) \\
0(0)\end{array}$ & $\begin{array}{l}8(250) \\
0(0)\end{array}$ & $\begin{array}{l}8(250) \\
2(50.0)\end{array}$ & & \\
\hline Diploms & $2(5.6)$ & $2(5.6)$ & $2(5.6)$ & $10(27.8)$ & $\begin{array}{l}20 \\
(55.8)\end{array}$ & 28.128 & 0.000 \\
\hline Degree & $0(0)$ & $20(5.6)$ & $80(22.6)$ & $98(27.7)$ & $\begin{array}{l}156 \\
(44.1)\end{array}$ & & \\
\hline $\begin{array}{l}\text { Moster } \\
\text { Type of Seholars }\end{array}$ & $\begin{array}{l}0(0) \\
\text { ahip }\end{array}$ & $2(11,1)$ & 2 (11.1) & $6(33.3)$ & $8(444)$ & & \\
\hline गागाN & $0(0)$ & $10(5.6)$ & $38(21.1)$ & $56(31,1)$ & \multirow{3}{*}{$\begin{array}{l}76 \\
(42.2) \\
24 \\
(37.5) \\
84 \\
(51.2)\end{array}$} & 14998 & 0.059 \\
\hline JPA & $0(0)$ & $4(6.3)$ & $10(15.6)$ & $26(40.6)$ & & & \\
\hline Others & $2(1.2)$ & $10(8.1)$ & $36(220)$ & $32(19.5)$ & & & \\
\hline $\begin{array}{l}\text { Valid licence } \\
1-2 \text { years }\end{array}$ & $O(0)$ & $4(2,1)$ & $34(18.1)$ & $54(28.7)$ & \multirow{3}{*}{$\begin{array}{l}96 \\
(51.1) \\
70 \\
(39.3) \\
18 \\
(42.9)\end{array}$} & \multirow[t]{3}{*}{20.909} & \multirow[t]{3}{*}{0.007} \\
\hline $3-5$ yess & $2(1.1)$ & $16(9.0)$ & $36(20.2)$ & $54(30.3)$ & & & \\
\hline $6-8$ years & $O(0)$ & $4(9.5)$ & $14(33.3)$ & $6(14.3)$ & & & \\
\hline $\begin{array}{l}\text { Driving experien } \\
\text { <1 yesrs }\end{array}$ & nae & $4(6.5)$ & $8(129)$ & $16(25.8)$ & \multirow{4}{*}{$\begin{array}{l}32 \\
(51.6) \\
118 \\
(46.5) \\
30 \\
(349) \\
4(667)\end{array}$} & \multirow[t]{4}{*}{34.589} & \multirow[t]{4}{*}{0.001} \\
\hline $2-5$ yess & $0(0)$ & $12(47)$ & $48(189)$ & $76(299)$ & & & \\
\hline $6-9$ years & $O(0)$ & $8(7.0)$ & $28(32.6)$ & $22(25.6)$ & & & \\
\hline$>10$ years & $0(0)$ & $2(33.3)$ & $O(0)$ & $0(0)$ & & & \\
\hline
\end{tabular}

Table 2 shows the socio-demographic data and the frequency use of the seat belt. the chi-square test was used to determine the association between the socio-demographic and the frequency of seat belt utilization. There are two variables related which are the sociodemographic and the frequency of the seat belt utilization. The result revealed that there was a significant relationship between some variables with the frequency use of seat belt. The result revealed the significant relationship between the gender and the frequency use of seat belt where $x^{2}=10.481$ and $p=0.033$. The result also revealed there is also significant relationship between other two variables and the frequency use of seat belt, age $\left(x^{2}=36.728\right.$ and $p=0.000)$, marital status $\left(x^{2}=218.986\right.$ and $\left.p=0.000\right)$, and educational status $\left(x^{2}=28.128\right.$ and $p=0.000$ ). Hence, the null hypothesis was accepted and alternate hypothesis was rejected. However, the result also revealed no significant relationship between the type of scholarship and the frequency use of seat belt where $x^{2}=24.988$ and $p=0.059$. Hence, the null hypothesis was rejected and alternate hypothesis was accepted. Reported seat belt 
utilization rates vary depending on the country. Comparatively, in most industrialised countries much higher seat belt utilization rates have been reported, such as in Arab Saudi, the seat belt utilization rates for drivers were $33 \%$ and $87 \%$ respectively in two Riyadh district (Bendak, 2005). They believed that the factor that may contribute to the higher rate of seat belt use in urban areas is the cultural differences. Seat belt utilization rates vary depending on the country as some findings found the different findings may be due to cultural differences, social demographic, difference government policy and difference law enforcement. Ethnic, gender, racial, socioeconomic variety, the way of different culture lives, belief and religious can be included in cultural differences. These different cultures may represent the driver attitudes and behaviours. Some study suggested that different social and cultural differences also influence driver personality. Social factors such as the attitudes and behaviour seems to affect seat belt utilization.

This study found that about $49.1 \%$ of female drivers and $40.2 \%$ of male drivers who always use their seat belt while driving. Both genders has low rate of seat belt use which is not more than $50 \%$ of seat belt use. This low finding also similar to Mohammadi (2011) who reported that, in Iran, females (37.0\%) were higher rate in travelled belted compared to male (11.0\%). Lapparent (2008) noticed that women drivers have a higher probability to fasten the safety belt because it can diminish significantly the probability of severe accident compared to men. Men are said to have significantly higher risk of crashes compared to women (Routley et al., 2008). This is because men are braver in taking risk to violate the seat belt law and engaging with unsafe driving behaviour.

Lapparent (2008) found that the probability to fasten the safety belt increases as the people get older. Similar to finding of Kim, Depue, Spence, \& Reine (2009), they found that low seat belt utilization is associated with younger age. However, this study revealed that only $45 \%$ of educated young adult aged of 18 to 35 years was always use seat belt. There was only $0 \%$ who was never use seat belt. This low rate of compliance towards seat belt use is crucial as Mohammadi (2011) who also found that more than $50 \%$ of young drivers at the age of 18 to 24 years travel unbelted in urban environment. Young men have the lower rate in seat belt use as they are braver in taking risk to violate the seat belt law and engaging with unsafe driving behaviour. The driver behaviour such as higher sensations seekers reported to be more likely to do not always use seat belt.

We found that the variable of marital status of the drivers is a statistically significant related to the seat belt utilization. Reported most of drivers who always use seat belt was high in divorced or widowed categories $(50.0 \%)$ and single categories $(46.8 \%)$ compared to married $(25.0 \%)$. Majority of single or unmarried drivers preferred to use seat belt when driving compared to married. This means that unmarried drivers used to be careful from being fined or stopped by police due to unbelted. However, Olukoga et al. (2011) found that marital status of the drivers did not predict the frequency of seat belt use whether a driver sometimes or always use seat belt.

As the education levels of the drivers increase, the seat belt use rate also increases in percentage. Simsekoglu \& Lajunen (2009) found out that seat belt use increase with the 
increase of education level. The educated persons reported to have a better driving behaviour which includes the using of seat belt when driving. Therefore, high educational level is likely to influence the seat belt use. This can be concluded that increase in the level of education contributes to increase in the seat belt usage which leads to decrease in number of crashes and severities. Demirer, Durat, \& Hasimoglu (2012) found that as the education level increases, the belief about seat belt protection against accident will also increase. They also found that most of the participants also claimed that they would like to use seat belt as if the problem of discomfort was overcome. However, the finding revealed that $55.6 \%$ of drivers who always seat belt had diploma educational status was the highest compared to degree $(44.1 \%)$ and master $(44.4 \%)$. This finding is opposite to the other findings might be due to the unequally distributed data whereby there is small ratio master and diploma participants involved in this study. This study would like to suggest for further research to investigate this relationship in Malaysia context.

\subsection{Conclusion}

As a conclusion, even though $100 \%$ of the respondents have scored a good quality of life and $98 \%$ satisfied with their health, yet they were not fully utilizing the seat belt. This situates them at higher risk of injuries and fatalities. Based on these results, concerted efforts are needed to improve the seat belt utilization in the driving population in the country which is one of the essential components in the human's daily living activities. Proper approach needs to be in place to tackle the 'imbalance' between good quality of life and perfect driving behaviour.

\section{Acknowledgement}

This study would like to thank the Research Management Institute (RMI) and all staff of the Faculty of Health Sciences UiTM Puncak Alam for continuous support in staff research and development. This study also would like to thank the Land Public Transport Commission also known as SPAD and PROTON Professor Office for their direct and indirect support. This study were funded by Fundamental Research Grant Scheme (FRGS) under the Ministry of Education (MOE) Malaysia; (600-RMI/FRGS 5/3 (118/2013).

\section{References}

Bendak, S. (2005). Seat belt utilization in Saudi Arabia and its impact on road accident injuries. Accid Anal Prev, 37(2), 367-371. doi: doi: 10.1016/j.aap.2004.10.007

DeCarlo, D. K., Scilley, K., Wells, J., \& Owsley, C. (2003). Driving Habits and Health-Related Quality of Life in Patients with Age-Related Maculopathy. Optometry \& Vision Science, 80(3), 207 - 213. 
Demirer, A., Durat, M., \& Hasimoglu, C. (2012). Investigation of seat belt use among the drivers of different education levels. Safety Science, 50, 1005-1008.

Hauswald, M. (1997). Seat Belt Use In A Developing Country: Covert Noncompliance With A Primary Enforcement Law In Malaysia. Accident Analysis and Prevention, 29(5), 695-697.

Kim, S., Depue, L., Spence, L., \& Reine, J. (2009). Analysis of teenage seat belt use: From the 2007 Missouri high school seat belt survey. Journal of Safety Research, 40, 311-316.

Kulanthayan, S., Raha, A. R., Law, T. H., \& Umar, R. S. R. (2004). Seat Belt Use Among Cars Users in Malaysia. IATSS Research 28(1), 19-25.

Kulkarni, V., Kanchan, T., Palanivel, C., Papanna, M. K., Kumar, N., \& Unnikrishnan, B. (2013). Awareness and practice of road safety measures among undergraduate medical students in a South Indian state. Journal of Forensic and Legal Medicine, 20, 226-229.

Lapparent, M. d. (2008). Willingness to use safety belt and levels of injury in car accidents. Accident Analysis and Prevention, 40, 1023-1032. doi: 10.1016/j.aap.2007.11.005

Masuri, M. G., Dahlan, A., Danis, A., \& Md Isa, K. A. (2015). Public Participation in Shaping Better Road Users in Malaysia. Procedia - Social and Behavioral Sciences, 168(0), 341-348.

Masuri, M. G., Dahlan, A., Danis, A., \& Md Isa, K. A. (2015). Regeneration of Road System in the Urban Environment: Will Rehabilitation Components Orientate Road Users? Procedia - Social and Behavioral Sciences, 170(0), 700-708. doi: http://dx.doi.org/10.1016/j.sbspro.2015.01.072

Masuri, M. G., Md Isa, K. A., \& Mohd Tahir, M. P. (2012). Children, Youth and Road Environment: Road Traffic Accident. Procedia - Social and Behavioral Sciences, 38(0), 213-218.

Md Isa, K. A., Masuri, M. G., Abd Aziz, N. A., Md Isa, N. N., Hazali, N., Mohd Tahir, M. P., et al. (2012). Mobile Phone Usage Behaviour while Driving among Educated Young Adults in the Urban University. Procedia - Social and Behavioral Sciences, 36(0), 414-420.

Mohamed, N., Yusoff, M. F. M., Batcha, W. A., Othman, I., \& Abdullah, I. (2010). Seatbelt Wearing Compliance Among Road Users in Putrajaya. In I. 978-983-44643-2-5 (Ed.), MRR 13/2009. Kajang, Selangor Darul Ehsan.

Mohammadi, G. (2011). Prevalance of seat belt and mobile phone use and road accident injuries amongst college students in Kerman, Iran. Chinese Journal of Traumatology 14(3), 165-169.

Ng, C. P., Law, T. H., Wong, S. V., \& Kulanthayan, S. (2013). Factors related to seatbelt-wearing among rear-seat passengers in Malaysia. Accident Analysis and Prevention, 50, 351-360.

Olukoga, A., Legall, G., \& Odekunle, A. (2011). Pattern of seat belt use by drivers in Trinidad and Tobago, West Indies. BMC Research Notes 2011, 4:201, 4(201), 1-6.

Rakauskas, M. E., J.Ward, N., \& Gerberich, S. G. (2009). Identification of differences between rural and urban safety cultures. Accident Analysis and Prevention, 41, 931-937.

Redhwan, A., \& Karim, A. (2010). Knowledge, Attitude and Practice Towards Road Traffic Regulations Among University Students, Malaysia. The Internal Medical Journal Malaysia, 1, 29-34. 
Wan Ahmad Kamal, W.N.H., et.al. / Asian Journal of Quality of Life, AjQoL, 2(7), Jul / Sep 2017 (p.29-37)

Routley, V., Ozanne-Smith, J., Li, D., Yu, M., JianyueWang, Zhang, J., et al. (2008). China belting up or down? Seat belt wearing trends in Nanjing and Zhoushan. Accident Analysis and Prevention, 40, 1850-1858.

Simsekoglu, Ö., \& Lajunen, T. (2009). Relationship of seat belt use to health and driver behavior. Transportation Research, 12(Part F), 235-241. 